\title{
Training to Use Motivational Interviewing Techniques for Depression: A Cluster Randomized Trial
}

\author{
Robert D. Keeley, MD, Brian L. Burke, PhD, David Brody, MD, Sona Dimidjian, PhD, \\ Matthew Engel, MPH, Caroline Emsermann, MS, Frank deGruy, MD, \\ Marshall Thomas, MD, Ernesto Moralez, MPH, Steve Koester, PhD, \\ and Jessica Kaplan, $B A$
}

Objective: The goal of this study was to assess the effects of training primary care providers (PCPs) to use Motivational Interviewing (MI) when treating depressed patients on providers' MI performance and patients' expressions of interest in depression treatment ("change talk") and short-term treatment adherence.

Methods: This was a cluster randomized trial in urban primary care clinics (3 intervention, 4 control). We recruited 21 PCPs (10 intervention, 11 control) and 171 English-speaking patients with newly diagnosed depression ( 85 intervention, 86 control). MI training included a baseline and up to 2 refresher classroom trainings, along with feedback on audiotaped patient encounters. We report summary measures of technical (rate of MI-consistent statements per 10 minutes during encounters) and relational (global rating of "MI Spirit") MI performance, the association between MI performance and number of MI trainings attended $(0,1,2$, or 3$)$, and rates of patient change talk regarding depression treatments (physical activity, antidepressant medication). We report PCP use of physical activity recommendations and antidepressant prescriptions and patients' short-term physical activity level and prescription fill rates.

Results: Use of MI-consistent statements was $26 \%$ higher for MI-trained versus control PCPs $(P=$ $.005)$. PCPs attending all 3 MI trainings $(n=6)$ had $38 \%$ higher use of MI-consistent statements $(P<$ $.001)$ and were over 5 times more likely to show beginning proficiency in MI Spirit $(P=.036)$ relative to control PCPs. Although PCPs' use of physical activity recommendations and antidepressant prescriptions was not significantly different by randomization arm, patients seen by MI-trained PCPs had more frequent change talk $(P=.001)$. Patients of MI-trained PCPs also expressed change talk about physical activity 3 times more frequently $(P=.01)$ and reported more physical activity $(3.05$ vs 1.84 days in the week after the visit; $P=.007)$ than their counterparts visiting untrained PCPs. Change talk about antidepressant medication and fill rates were similar by randomization $\operatorname{arm}(P>.05$ for both $)$.

Conclusions: MI training resulted in improved MI performance, more depression-related patient change talk, and better short-term adherence.(J Am Board Fam Med 2014;27:621-636.)

Keywords: Depressive Disorder, Medical Education, Motivational Interviewing, Patient Adherence, Randomized Controlled Trial

Motivational Interviewing (MI) is a "collaborative conversation style for strengthening a person's own motivation and commitment to change."1 General

This article was externally peer reviewed.

Submitted 16 December 2013; revised 16 May 2014; accepted 19 May 2014.

From the Department of Family Medicine (RDK, CE, FdG), the Department of Internal Medicine (DB), the Department of Psychiatry (MT), and the Department of Health and Behavioral Sciences (SK), University of Colorado, Denver; Denver Health, Denver, CO (RDK, DB, ME); the Department of Psychology, Fort Lewis College, Durango, medical settings have begun adopting MI from its origins in the specialty milieu to help address a broad range of problematic health behaviors. ${ }^{2} \mathrm{Un}$ -

CO (BLB); the Department of Psychology and Neuroscience, University of Colorado, Boulder (SD); and Emory University School of Medicine (JK).

Funding: Funding for this study was provided by the National Institute of Mental Health grant nos. K23MH0829972 and 3K23082997-S1; National Institutes of Health/National Center for Advancing Translational Sciences Colorado CTSI grant no. KL2 TR000156 (to CE).

Conflict of interest: none declared. 
Figure 1. Theoretical model of how motivational interviewing (MI) training influences patient treatment and health outcomes.

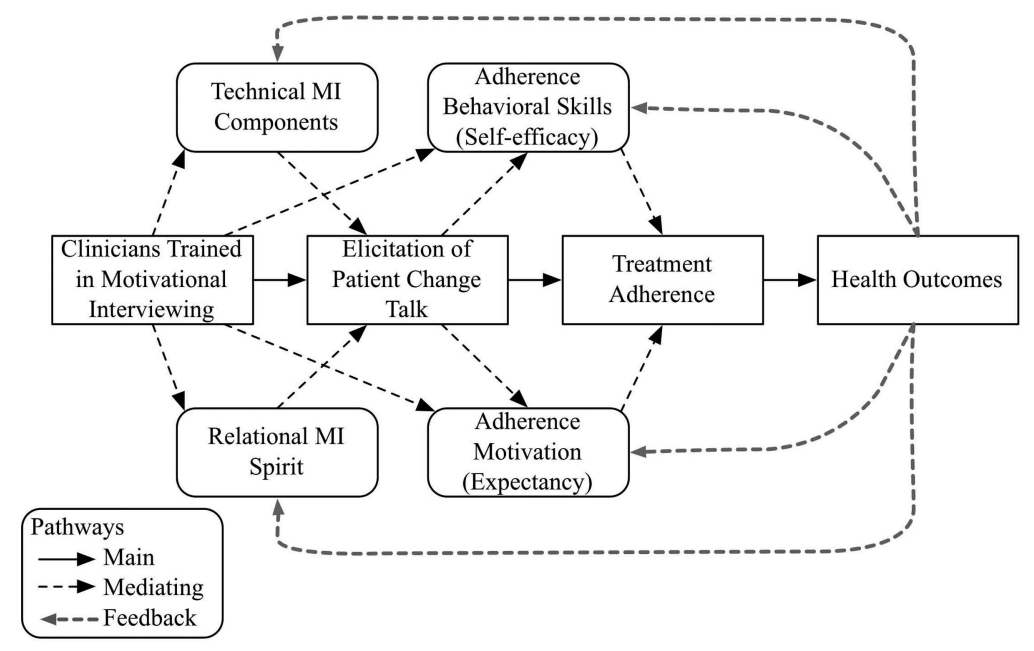

fortunately, published training approaches have not yet demonstrated that primary care providers (PCPs) learn MI and implement it in clinical practice over time, nor have they provided evidence that MI training for PCPs is linked to treatment adherence and clinical outcomes. ${ }^{3,4}$ In this study we investigated whether a multifaceted MI training improved (1) PCPs' MI performance during index visits with patients with newly diagnosed depression; (2) subsequent outcomes related to patients' expressed interest ("change talk") in improving this condition; and (3) short-term adherence to treatment $^{5}$ (Figure 1).

Depression is projected to become the leading cause of disability worldwide by $2030^{6}$ and is often treated, at least in part, in primary care. ${ }^{7,8}$ In general, poor depression outcomes in primary care ${ }^{9-11}$ are in part because of pervasive nonadherence to depression treatment, which is associated with lower recovery rates. ${ }^{12,13}$ Multiple training approaches to improve PCPs' treatment of depression have not translated into better treatment adherence

Prior Presentation: This content was presented (by RDK) as a podium presentation, "Motivational Interviewing for Depression in Primary Care: Training and Pilot Outcomes," at the North American Primary Care Research Group Conference, November 14, 2010, Seattle, WA.

Disclaimer: Contents are the authors' sole responsibility and do not necessarily represent the official views of the National Institutes of Health.

Corresponding author: Robert D. Keeley, MD, University of Colorado Denver, Mail Stop F-496, Academic Office 1, 12631 E. 17th Ave, Aurora, CO 80045 (E-mail: robert.keeley@ucdenver.edu). or clinical outcomes. ${ }^{14,15}$ In theory, MI may offer an ideal framework to address the problem of nonadherence to depression treatments. ${ }^{16}$ In practice, $\mathrm{MI}$ as a pretreatment for cognitive behavioral therapy for anxiety seemed to increase active engagement in therapy. ${ }^{17}$

With this randomized controlled trial (RCT) of MI training for PCPs we attempted to support PCPs in learning and using MI when discussing depression. Recent reviews describe positive effects of MI on sedentary lifestyle, dental caries, hypertension, human immunodeficiency virus viral load, obesity, and substance use; the effect on most outcomes is likely secondary to improved treatment adherence. ${ }^{18,19}$ While most of the studies used mental health professionals or nurses to provide MI, PCPs may also exert similar influence when trained in MI. ${ }^{19}$ Training PCPs to learn MI may enable them to positively influence a broad range of problematic health behaviors that are prevalent in primary care settings. Null effects reported in previous RCTs of training PCPs to learn and implement MI may be because of teaching an abridged form of MI or omitting training components that have demonstrated effectiveness in specialty settings. ${ }^{3}$

Previous research suggests that a baseline workshop alone is not sufficient to impart an enduring understanding of the techniques and spirit of MI. ${ }^{20,21}$ Ongoing feedback regarding specific MI skills, consultation phone calls, ${ }^{12,16}$ and refresher courses $^{22,23}$ are also recommended. Therefore, we 
Figure 2. Flow diagram of primary care provider progress through the phases of the randomized trial. MI, motivational interviewing.

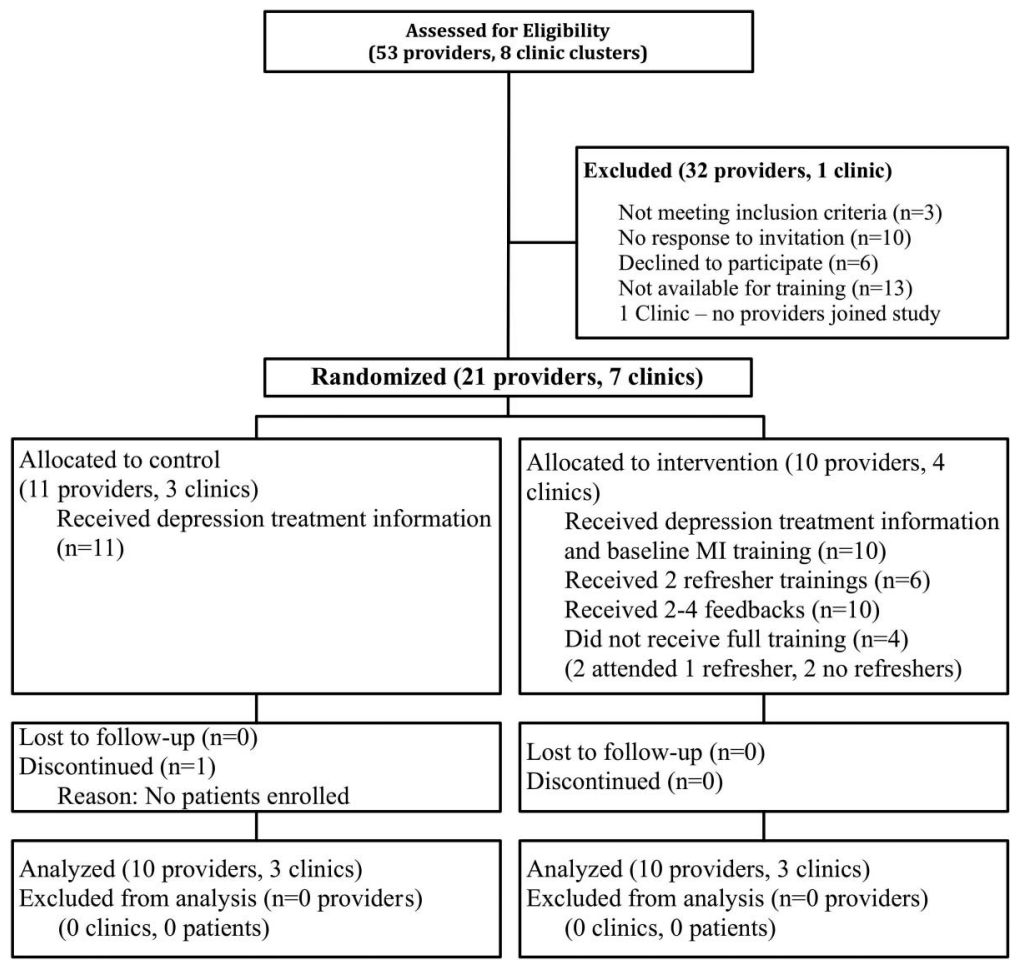

translated approaches from the substance abuse treatment arena into an MI training strategy for PCPs. Because communication training for PCPs should improve intermediate patient-level factors that are linked to important adherence and clinical outcomes, we also assessed patient-level factors. ${ }^{4}$ For instance, PCPs' MI performance ${ }^{24}$ may help elicit a type of patient language called "change talk," or utterances in favor of change, ${ }^{25}$ which often predicts improvements in target problematic health behaviors such as treatment adherence. ${ }^{5,26,27}$

We hypothesized that, relative to their counterparts receiving no MI training, those PCPs randomized to MI training would exhibit superior MI performance during clinical encounters with patients with a new diagnosis of depression and that their patients would voice more overall depressionrelated change talk and exhibit better short-term treatment adherence. Because all PCPs participated in training for standard management of depression, we theorized no difference by randomization arm in whether the PCP provided a prescription for antidepressant medication or recommended physical activity. We also explored the association between number of $\mathrm{MI}$ trainings $(0,1,2$, or 3$)$ and $\mathrm{MI}$ performance.

\section{Methods}

\section{Participants and Enrollment Process}

Setting

This pragmatic cluster trial took place from April 2010 to December 2012 in primary care clinics at a federally qualified community health care system in Denver, Colorado (Figure 2).

\section{PCP Enrollment}

From May to June 2009, experienced PCPs were E-mailed twice to consider participation "in a training for a new counseling method for treating depression" and to be randomized to the intervention or control arm. Inclusion criteria included working at 1 of 8 primary care clinics in the system, a minimum of $30 \%$ effort conducting outpatient clinical work, and availability for a 1-day training in late July 2009. All participating PCPs signed a written consent. PCPs were remunerated at a rate of $\$ 65 /$ hour; funds were placed in a professional spending account for time spent in MI classroom trainings.

\section{Patient Enrollment}

Patients were enrolled between April 2010 and March 2012. Consecutive English-speaking pri- 
mary care patients aged $\geq 18$ years were contacted by telephone before a scheduled primary care visit. We screened for exclusion criteria and invited those not excluded to complete a recorded partial waiver of consent and a stage I depression screen (2-item Patient Health Questionnaire). ${ }^{28}$ Consenting patients with a positive screen were met at the clinic before their visit by a recruiter to obtain written consent and complete the 9-item Patient Health Questionnaire (PHQ-9). ${ }^{29}$ Patients whose PHQ-9 score was $\geq 10$, indicating probable major depression, were enrolled. PCPs and patients were notified just before the encounter regarding the depression severity level, and the visit was audiotaped.

Exclusion criteria included age $<18$ years, taking medication for depression within 3 months or current psychotherapy, currently pregnant or breastfeeding, life-threatening physical disease, severe suicidal ideation, diagnosed bipolar disorder, or current psychosis. All patient participants received a \$20 gift card for completing the baseline surveys. Clinical care was not reimbursed by this study. The protocol was approved by the Colorado Multiple Institutional Review Board (COMIRB no. 08-1282) and is registered at clinicaltrials.gov (NCT01114334).

\section{Randomization}

Before randomization, participating PCPs' 7 home clinics were stratified by the predominant race/ethnicity of the adult patients at the clinicHispanic (>70\%), non-Hispanic black $(>70 \%)$, or non-Hispanic white $(>50 \%)$ - because adherence to antidepressant medication and depression outcomes may be worse for members of racial/ethnic minority groups. ${ }^{30-33}$ Two smaller clinics from adjacent neighborhoods with similar patient populations were combined for randomization purposes. Clinics in each stratum were randomly assigned to a condition, and the participating PCPs in each clinic were assigned to the same condition. PCPs were not blinded to training assignment. Patients were blinded to randomization status. An independent provider conducted the randomization using the RAND() function (Microsoft Excel; Microsoft Corp., Redmond, WA).

\section{PCP Training}

Standard Management of Depression

Enrolled PCPs received a copy of the American Psychiatric Association's Practice Guideline for the Treatment of Major Depressive Disorder ${ }^{5}$ and a summary slide show describing antidepressant therapy and evidence-based psychotherapy as primary treatments, with physical activity as a potentially beneficial adjunct. The guideline recommended 3 follow-up visits over the 12-week acute treatment phase, additional follow-up visits as needed during the 24-week continuation treatment phase, and prescription of antidepressant medication over 36 weeks. No payment was provided for participating in depression management training.

\section{Motivational Interviewing for Depression}

The MI training approach was translated from the substance abuse field and included interactive learning for most of the core MI skills. The emergent theory of MI proposes 2 domains: a technical domain targeting the differential evocation and reinforcement of patient "change talk" and a relational domain (dependent in part on sound technical performance) emphasizing empathy and the interpersonal spirit of MI. ${ }^{24}$ An 8-hour classroom training on July 25, 2009, consisted of a brief overview of MI, videos and discussion of core MI skills and "MI spirit," and skill-building practice. Intervention PCPs learned how to use open-ended questions, affirmations, reflective statements, and summaries to elicit change talk, to implement the elicit-provide-elicit technique, and to craft action plans. PCPs practiced using 0 to 10 Rulers to assess and increase patient importance and confidence in changing. (See Appendix 1 for definitions of MI components.) For all training sessions, the second author (BLB) was the lead trainer, and the first author (RDK) assisted. PCPs received a pocket card outline for a 4-visit episode of care (Table 1).

Four-hour refresher trainings were offered on November 22, 2009, and July 11, 2010. During the first refresher, open-ended questions, affirmations, reflective statements, and summaries were reviewed and the PCPs practiced the elicit-provide-elicit technique. At the second refresher, participants read transcripts and listened to audiotapes to practice identifying change talk, and they learned to respond to change talk using the "EARS" technique (elaborate, affirm, reflect, summarize). 
Table 1. Four-visit Episode of Care
Baseline visit goals:
- Build relationship using OARS*
- Provide symptom feedback
○ Ask permission
○ Provide depressive symptom score
○ Ask: "What do you think of this result?"
- Elicit-Provide-Elicit**
- Develop follow-up and action plan
Follow-up visit goals:
- Enhance treatment adherence with "rulers"***
- Explore other relevant behavioral targets
- Foster behavioral activation and problem solving

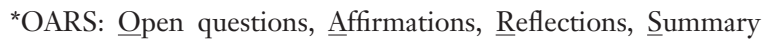
statements.

${ }^{* *}$ Elicit-Provide-Elicit: A method of asking about current knowledge, providing information with permission, and asking patient to reflect on the new information. Goal is to elicit change talk.

*** Rulers: 10 point scale of patient's confidence in and perceived importance of behavior change.

The primary investigator (RDK) provided (via E-mail and in person) feedback for MI-trained PCPs regarding their audiotaped encounters (2 to 4 feedbacks per PCP) during the first 14 months. ${ }^{21,34}$ Feedback consisted of presenting summaries and interpretations of utterances made by PCPs. The PCP was invited to respond to the feedback and to choose which MI skill(s) to try and improve before the next encounter.

\section{Measures}

\section{PCP MI Training Outcomes}

Technical Performance. Trained coders (see Appendix 2 for descriptions of coder training and reliability scores) used the Motivational Interviewing Treatment Integrity (MITI) code 3.1.1 $1^{35}$ to evaluate provider language within complete encounters (ranging 7.62 to 58.38 minutes in length). A summary measure of technical performance, the frequency of MI-consistent language (fMICO) was calculated by summing the MITI componentsopen-ended questions, reflective statements, and MI-adherent statements (Appendix 1) — then calculating the mean rate per 10 encounter minutes. ${ }^{36}$ We also analyzed individual MITI component counts per encounter and MITI ratios (eg, percentage of MI-adherent statements; see Table 4 for definitions) recommended in the specialty literature. ${ }^{35}$
Relational Performance. MITI global scores for collaboration, autonomy support, evocation, direction, and empathy (ranging form 1 to 5; higher scores are better) were determined, and we calculated a summary measure of relational performance, "MI spirit," by averaging the collaboration, autonomy, and evocation scores. These results were measured against beginning proficiency thresholds recommended for substance abuse counselors who have completed basic MI training. ${ }^{37}$ For individual global ratings and MI spirit, a threshold of $\geq 3.5$ defines "beginning proficiency." We examined the association between the number of MI training sessions attended (3, 2, 1, or 0$)$ and fMICO and beginning proficiency in MI Spirit.

\section{PCP Depression Management Training Outcomes}

Depression-Related Treatment Advice. Encounters were assessed for PCP recommendation to increase physical activity or to take a prescription for an antidepressant medication. Effectiveness of the depression management training was not otherwise evaluated.

\section{Patient Outcomes}

Change Talk. The MI Skills Code $2.1^{38}$ was used to categorize patient change talk. Change talk is patient language in favor of a positive behavior change, as opposed to "sustain talk" toward maintaining a negative behavior. ${ }^{38}$ Total change talk comprised change talk for adherence to evidencebased treatments for depression (antidepressant medication, specialty mental health counseling, and physical activity) and for nonharmful behaviors the patient deemed to enhance mood (eg, visiting friends).

We calculated the mean rate of change talk statements per 10 minutes of the encounter to obtain standardized measures of patient change talk. ${ }^{25}$ We report both treatment-specific and total measured change talk. Because specialty mental health counseling was not broadly available during the RCT, we do not report referral rates, change talk specific to counseling, or follow-up on counseling referrals.

Treatment Adberence. Among patients we assessed (1) whether a prescription for an antidepressant medication was filled (pharmacy records) ${ }^{27}$ and (2) the number of days of physical activity lasting at 
least 30 minutes during the week after the index visit (self-report). ${ }^{39}$

\section{Analyses}

For count or frequency and dichotomized outcomes, multivariate linear mixed and mixed effects logistic regression models, respectively, determined differences by patient group. For all models we clustered patients within PCP as a random effect. Because intervention encounters were, on average, slightly longer than control encounters, we adjusted MITI component counts for clinical encounter length in seconds. We adjusted the intent-totreat analyses for the intervention as intended, unadjusted for covariates.

We developed models adjusted for 4 possible patient- and PCP-level covariates associated in the literature $^{40}$ with provision of MI (PCP training level), ${ }^{19}$ with differences in MI effectiveness (patient race/ethnicity), ${ }^{24}$ or with differential adherence to evidence-based depression treatment (patient age, patient sex). ${ }^{41} \mathrm{We}$ included possible covariates that were associated with intervention or outcome at $P<.20$. Statistical associations were made at the $\alpha=0.05$ level using 2-tailed tests. We used SAS version 9.3 (SAS, Inc., Cary, NC) for all analyses.

\section{Results}

\section{PCP and Patient Enrollment and Randomization}

We invited 53 PCPs to participate. Three providers were not eligible, $10 \mathrm{did}$ not respond to the invitations, 13 had scheduling conflicts with the baseline training, and 6 declined (1 refused randomization, 2 were worried about extra workload, and 3 provided no reason). In total, 21 providers were recruited and randomized (10 to MI training, 11 to control). The providers were distributed as follows: 2 clinics with 1 provider, 1 clinic with 2 providers, 3 clinics with 4 providers, and 1 clinic with 5 providers. One control PCP was excluded because no patients were recruited over the study period.

All 10 providers randomized to the MI training attended the baseline training, 6 attended both refreshers, 2 just one refresher, and 2 neither refresher (Figure 2). We estimate that PCPs responded to feedback pertaining to their MI performance about $30 \%$ of the time by acknowl- edging the information or describing how they would try to improve.

We enrolled 175 patients (88 to MI training, 87 to control) between April 2010 and March 2012. Four audiotapes were inadvertently not activated, leaving 171 recordings for analysis ( 85 intervention and 86 control).

\section{Patient and Provider Descriptions}

Providers averaged about 48 years of age and reported minimal or no previous MI training (Table 2). $\mathrm{Pa}$ tients averaged 48 years of age and about $50 \%$ reported a household income $<\$ 10,000$, and about half were obese (body mass index $>30 \mathrm{~kg} / \mathrm{m}^{2}$ ). Patients averaged mild to moderately severe depressive symptoms (mean PHQ-9 score of 15.7). There were no significant differences in provider or patient characteristics by randomization arm (Table 2).

\section{Reliability and Coefficients of Intraclass Correlation}

We calculated 16 reliability scores: 13 were rated "good" to "excellent" and 3 were rated "fair." 42 The coefficients of intraclass correlation for fMICO rate and MI spirit were 0.009 (small) and 0.48 (large), ${ }^{43}$ respectively (see Appendix 2 for all coefficients of intraclass correlation).

\section{Provider Outcomes}

\section{Summary Technical Performance}

Clinical encounters averaged 25.2 minutes (standard deviation [SD], 8.5). The intervention visits (26.2 minutes) were slightly longer than the control visits (24.1 minutes) $(P=.02)$. In the intention-totreat analysis, PCPs assigned to the MI training averaged higher rates of MI-consistent language compared with those who received no training (fMICO, 8.80 [SD, 4.16] vs 6.98 [4.14]; $P=.005$; Cohen's d clinical effect size $=0.44)^{44}$ (Table 3). Results adjusted for covariates were similar.

\section{Summary of Relational Performance}

Over twice as many MI-trained as untrained PCPs seemed to demonstrate beginning proficiency in MI spirit (37\% vs $15 \%$ ), although the difference was not significant (adjusted odds ratio [AOR], $3.28 ; 95 \%$ confidence interval $[\mathrm{CI}], 0.83-12.90$ ) (Table 3). 
Table 2. Baseline Characteristics of the Provider and Patient Participants

\begin{tabular}{|c|c|c|}
\hline Characteristics* & Intervention $^{\dagger}$ & Control $^{\ddagger}$ \\
\hline Providers & $\mathrm{n}=10$ & $\mathrm{n}=11$ \\
\hline Age, years & $49.2(7.6)$ & $47.4(8.6)$ \\
\hline Female sex (n) & 6 & 8 \\
\hline \multicolumn{3}{|l|}{ Ethnicity (n) } \\
\hline White & 8 & 10 \\
\hline Hispanic & 1 & 2 \\
\hline \multicolumn{3}{|l|}{ Specialty (n) } \\
\hline Internal medicine & 3 & 2 \\
\hline Family medicine & 4 & 6 \\
\hline Nurse practitioner & 2 & 2 \\
\hline Physician's assistant & 1 & 1 \\
\hline Years in practice & $16.8(8.6)$ & $17.5(8.8)$ \\
\hline Previous MI training (hours) & $1.1(3.3)$ & $0.5(0.8)$ \\
\hline Patients $\$$ & $\mathrm{n}=85$ & $\mathrm{n}=86$ \\
\hline Clusters (n) & 10 & 11 \\
\hline Age, years & $51.5(7.9)$ & $45.3(7.3)$ \\
\hline Female sex, \% & $62.0(31.1)$ & $67.8(24.5)$ \\
\hline \multicolumn{3}{|l|}{ Race/ethnicity, \% } \\
\hline Non-Hispanic white & $17.6(13.7)$ & $26.0(14.6)$ \\
\hline Non-Hispanic black & $32.6(34.8)$ & $43.2(23.9)$ \\
\hline Hispanic & $38.2(31.4)$ & $25.2(26.4)$ \\
\hline Other & $11.7(9.8)$ & $5.6(7.7)$ \\
\hline \multicolumn{3}{|l|}{ Insurance, \% } \\
\hline Uninsured & $34.5(20.3)$ & $46.4(24.6)$ \\
\hline Private & $2.9(7.1)$ & $2.7(4.3)$ \\
\hline Public & $62.5(21.9)$ & $49.8(22.1)$ \\
\hline $\begin{array}{l}\text { Household income } \\
<\$ 10,000, \%\end{array}$ & $48.0(20.7)$ & $51.7(23.5)$ \\
\hline Employed & $39.9(23.9)$ & $47.6(14.1)$ \\
\hline Body mass index $\left(\mathrm{kg} / \mathrm{m}^{2}\right)$ & $31.5(3.9)$ & $32.9(3.3)$ \\
\hline Physical comorbidities" & $2.3(0.8)$ & $2.1(1.0)$ \\
\hline PHQ-9 score & $15.6(2.4)$ & $15.9(1.8)$ \\
\hline
\end{tabular}

Data are mean (standard deviation) of participants unless stated otherwise.

*The number of participating primary care physicians (PCPs) was distributed as follows: 2 clinics with $1 \mathrm{PCP}, 1$ with 2 PCPs, 3 with 4 PCPs, and 1 with 5 PCPs.

${ }^{+}$Motivational interviewing with standard management of depression training.

${ }^{\ddagger}$ Standard management of depression training alone.

${ }^{\S}$ Patient characteristics were analyzed by cluster. Data provided are per cluster.

"Comorbid categories were derived from abstracting the electronic medical record of up to 8 common chronic diseases in the patient problem list, including arthritis, asthma, chronic pain, congestive heart failure, chronic obstructive pulmonary disease, coronary heart disease, diabetes, and obesity (body mass index $\geq 30 \mathrm{~kg} / \mathrm{m}^{2}$ ). PHQ-9, 9-item Patient Health Questionnaire.

\section{Performance for Individual Technical and Relational Components}

The counts of 4 individual MITI components that were emphasized in at least $2 \mathrm{MI}$ classroom trainings (open questions, affirmations, complex reflections, and asking permission) occurred more often for MI-trained relative to untrained PCPs $(P<.05)$ (Table 4). Counts for those MITI components not targeted for improvement (support statements) or for reduction (MI nonadherent statements, closedended questions) were similar by randomization arm. Global "direction" rated significantly higher among the MI-trained PCPs (Table 4). There were no differences by randomization arm in beginning proficiency for any global scale or for MITI ratios.

\section{Comparisons of Technical and Relational MI Performance by Number of Trainings}

Relative to PCPs attending 1 or no MI trainings, those attending both refreshers demonstrated significantly greater $\mathrm{fMICO}$ scores $(\mathrm{d}=>0.7 ; P<$ .05). When comparing PCPs attending 3, 2, 1 , or 0 (control) MI classroom trainings, beginning proficiency in MI spirit was noted in $49.2 \%, 25.1 \%$, $18.5 \%$, and $14.7 \%$ of recorded encounters, respectively. Those attending 3 trainings were significantly more likely to exhibit beginning proficiency in MI spirit relative to control providers (AOR, 5.60; 95\% CI, 1.13-27.89) (Table 5).

\section{Treatment Advice}

Although recommending physical activity trended higher among MI-trained PCPs (AOR, 2.21; 95\% CI, 0.99-4.95), neither recommendation of physical activity nor prescribing antidepressant medication (AOR, 1.17; 95\% CI, 0.59-2.30) was significantly different by randomization arm (Table 3).

\section{Patient Outcomes}

Change Talk

Compared with their counterparts seeing untrained PCPs, patients visiting MI-trained PCPs made depression-related change talk statements over $100 \%$ more frequently (statements per 10 encounter minutes: $0.90 ; 95 \%$ CI, $0.71-1.10$ vs $0.44 ; 0.44-0.63$; $\mathrm{d}=0.51)$. The rate of change talk around physical activity showed similar relative improvement (statements per 10 encounter minutes: $0.30 ; 95 \%$ CI, $0.19-0.41$ vs $0.10 ;-0.01-0.21 ; \mathrm{d}=0.39$ ); however, the rate of change talk specific to antide- 
Table 3. Comparison of Mean Scores for Provider- and Patient-level Outcomes by Randomization Arm

\begin{tabular}{|c|c|c|c|c|}
\hline Provider- and Patient-Level Measures & $\begin{array}{c}\text { Intervention* Mean or } \\
\text { Proportion (SD) } \\
\mathrm{n}=85\end{array}$ & $\begin{array}{l}\text { Control }^{\dagger} \text { Mean or } \\
\text { Proportion (SD) } \\
\quad(\mathrm{n}=86)\end{array}$ & $\begin{array}{c}P \\
\text { Value }\end{array}$ & $\begin{array}{l}\text { Adjusted Odds Ratio or } \\
\text { Cohen's d }{ }^{* *}(95 \% \mathrm{CI})\end{array}$ \\
\hline \multicolumn{5}{|l|}{ Summary MI performance } \\
\hline Rate of MI-consistent statements ${ }^{\ddagger}$ & $8.80(4.16)$ & $6.98(4.14)$ & .005 & $\mathrm{~d}=0.44(0.13-0.74)$ \\
\hline \multicolumn{5}{|l|}{ Summary global rating } \\
\hline Beginning spirit in MI Spirit ( $\geq 3.5)$ & $0.37(1.01)$ & $0.15(0.59)$ & .083 & $3.28(0.83-12.90)$ \\
\hline \multicolumn{5}{|l|}{ Provider treatment advice } \\
\hline Recommendation for physical activity & $0.34(0.54)$ & $0.19(0.43)$ & .053 & $2.21(0.99-4.95)$ \\
\hline $\begin{array}{l}\text { Prescription for antidepressant } \\
\text { medication }\end{array}$ & $0.42(0.53)$ & $0.38(0.51)$ & .66 & $1.17(0.59-2.30)$ \\
\hline \multicolumn{5}{|l|}{ Frequency of patient change talk } \\
\hline $\begin{array}{l}\text { Rate of all depression treatment-related } \\
\text { change talk }\end{array}$ & $0.90(0.91)$ & $0.44(0.90)$ & .001 & $\mathrm{~d}=0.51(0.21-0.82)$ \\
\hline $\begin{array}{l}\text { Rate of change talk specific to physical } \\
\text { activity }\end{array}$ & $0.30(0.51)$ & $0.10(0.51)$ & .01 & $\mathrm{~d}=0.39(0.09-0.70)$ \\
\hline $\begin{array}{l}\text { Rate of change talk specific to } \\
\text { antidepressant medication }\end{array}$ & $0.25(0.47)$ & $0.15(0.46)$ & .17 & $\mathrm{~d}=0.21(-0.09$ to 0.51$)$ \\
\hline \multicolumn{5}{|l|}{ Treatment adherence } \\
\hline Days physically active in past week, ${ }^{\S} \mathrm{n}^{\mathbb{T}}$ & $3.05(2.83)$ & $1.84(2.75)$ & .007 & $\mathrm{~d}=0.42(0.11-0.72)$ \\
\hline Filled prescription, \% & $0.62(0.17)$ & $0.56(0.17)$ & .63 & $1.27(0.48-3.34)$ \\
\hline
\end{tabular}

Data are number (\%) of participants unless stated otherwise.

*Motivational interviewing (MI) with standard management of depression training.

${ }^{\dagger}$ Standard management of depression training alone.

${ }^{\ddagger}$ Mean rate of open questions, reflective statements, or MI-adherent statements per 10 minutes of the clinical encounter.

${ }^{\$}$ Physical activity was ascertained on average 5.4 days (standard deviation, 3.3 days) after the index encounter.

"Includes change talk regarding physical activity, antidepressant medication, specialty mental health counseling, and nonharmful behaviors the patient suggests might alleviate depressive symptoms.

II Days in the previous week during which patient engaged in at least 30 minutes of physical activity.

${ }^{* *}$ Clinical effect sizes based on Cohen d values: 0.2, small; 0.5, medium; 0.8, large. Clinical effect sizes based on odds ratio (OR): 1.29 , small; 1.88 , medium; 2.79 , large. $^{44}$

pressant medication was not significantly greater for patients visiting MI-trained PCPs (statements per 10 encounter minutes: 0.25 ; $95 \%$ CI, $0.15-0.35$ vs $0.15 ; 0.05-0.25 ; \mathrm{d}=0.21$ ) (Table 3 ).

\section{Treatment Adherence}

In the intent-to-treat analyses, intervention patients reported significantly more days performing $\geq 30$ minutes of physical activity in the week after their index visit (days of the week: 3.05 ; 95\% CI, 2.42-3.67) than their counterparts visiting untrained PCPs (days of the week: 1.84; 95\% CI, $1.18-2.51 ; \mathrm{d}=0.40)$. Patients randomized to intervention were not significantly more likely to fill an initial prescription for antidepressant medication (AOR, 1.27; 95\% CI, 0.48-3.43) (Table 3).

\section{Adverse Events}

No adverse events were reported.

\section{Discussion}

In this effectiveness trial of training experienced PCPs to learn and use MI, we analyzed index clinical encounters with newly diagnosed depressed patients and found that MI training was associated with enhanced MI performance and short-term, clinically relevant patient outcomes. Overall, MItrained PCPs voiced 26\% more MI-consistent language than their untrained counterparts; this is explained primarily by $\geq 60 \%$ increases in the provision of affirmations, asking permission to share information, and complex reflections. There was no evidence that MI training significantly influenced PCPs' treatment recommendation rates. $\mathrm{Pa}$ tients' number of activity-related change talk statements during the index visit and report of physically active days over the next week were significantly greater when patients visited MI-trained PCPs; however, neither medication-related change talk nor rates of obtaining medication were higher. 


\begin{tabular}{|c|c|c|c|}
\hline & \multicolumn{2}{|c|}{ Mean (SD) by Treatment Arm } & \multirow[b]{2}{*}{$P$ Value } \\
\hline & $\begin{array}{l}\text { Intervention* } \\
\quad(\mathrm{n}=85)\end{array}$ & $\begin{array}{l}\text { Control }^{\dagger} \\
(\mathrm{n}=86)\end{array}$ & \\
\hline Visit time (seconds) & $1571(480)$ & $1447(545)$ & .056 \\
\hline \multicolumn{4}{|l|}{ MI treatment integrity instrument component measure ${ }^{\ddagger}$} \\
\hline MI-adherent statements & $3.49(3.29)$ & $2.01(3.3)$ & .004 \\
\hline Asking permission ${ }^{\S \|}$ & $0.75(0.92)$ & $0.13(0.92)$ & $<.0001$ \\
\hline Affirmations ${ }^{\S \|}$ & $1.07(1.65)$ & $0.39(1.64)$ & .007 \\
\hline Emphasizing controll & $0.31(0.76)$ & $0.42(0.76)$ & .34 \\
\hline Support ${ }^{\|}$ & $1.35(1.91)$ & $1.08(1.91)$ & .36 \\
\hline MI nonadherent statements ${ }^{\dagger}$ & $3.14(7.11)$ & $3.62(7.05)$ & .66 \\
\hline Advising & $1.24(2.81)$ & $1.48(2.79)$ & .58 \\
\hline Confronting & $1.10(3.23)$ & $1.30(3.20)$ & .68 \\
\hline Directing & $0.75(1.80)$ & $0.84(1.80)$ & .76 \\
\hline Percent MI-Adherent & $56.04(63.41)$ & $37.69(61.62)$ & .07 \\
\hline Beginning proficiency for Percent MI-Adherent $(\mathrm{n} / \mathrm{N})^{\mathbb{I}}$ & $0 / 10$ & $0 / 10$ & - \\
\hline \multicolumn{4}{|l|}{ Questions } \\
\hline Closed & $29.85(20.76)$ & $25.93(20.65)$ & .22 \\
\hline Open $^{\S \|}$ & $5.87(3.87)$ & $4.5(3.87)$ & .02 \\
\hline Open questions $(\%)^{\mathbb{I}}$ & $16.97(10.59)$ & $15.37(10.58)$ & .32 \\
\hline Beginning proficiency for open questions $(\mathrm{n} / \mathrm{N})$ & $0 / 10$ & $0 / 10$ & - \\
\hline \multicolumn{4}{|l|}{ Reflections } \\
\hline Simple & $6.73(6.60)$ & $6.48(6.57)$ & .80 \\
\hline Complex ${ }^{\S} \|$ & $2.91(3.38)$ & $1.74(3.38)$ & .03 \\
\hline Complex reflection $(\%)^{\mathrm{q}}$ & $28.92(33.96)$ & $19.41(33.62)$ & .07 \\
\hline Beginning proficiency for complex reflections $(\mathrm{n} / \mathrm{N})$ & $2 / 10$ & $0 / 10$ & .47 \\
\hline \multicolumn{4}{|l|}{ Reflection-to-question ratio ${ }^{\mathbb{I}}$} \\
\hline Giving information & $20.16(11.78)$ & $20.86(11.75)$ & .70 \\
\hline \multicolumn{4}{|l|}{ Global ratings } \\
\hline Evocation & $3.00(2.08)$ & $2.52(2.07)$ & .127 \\
\hline Evocation: beginning proficiency ${ }^{\mathbb{I I}}$ & $3 / 10$ & $0 / 10$ & .21 \\
\hline Collaboration & $3.13(2.23)$ & $2.74(2.21)$ & .25 \\
\hline Collaboration: beginning proficiency ${ }^{\mathrm{TI}}$ & $3 / 10$ & $2 / 10$ & 1.00 \\
\hline Autonomy support & $3.21(1.75)$ & $2.79(1.74)$ & .11 \\
\hline Autonomy support: beginning proficiency & $1 / 10$ & $3 / 10$ & .58 \\
\hline Direction & $4.40(1.28)$ & $3.97(1.28)$ & .03 \\
\hline Direction: beginning proficiency $^{\ddagger}$ & $10 / 10$ & $8 / 10$ & .47 \\
\hline Empathy & $3.22(2.03)$ & $2.82(2.01)$ & .20 \\
\hline Empathy: beginning proficiency & $3 / 10$ & $2 / 10$ & 1.00 \\
\hline
\end{tabular}

Data are number (\%) of participants unless stated otherwise.

*Motivational interviewing (MI) with standard management of depression training.

${ }^{\dagger}$ Standard management of depression training alone.

${ }^{\ddagger}$ Language counts, frequencies, and global scores are derived from clustered analyses. For standardization purposes the language counts are adjusted for encounter length (seconds).

${ }^{\S}$ Motivational Interviewing Treatment Integrity (MITI) component was a focus in $>1$ MI classroom training.

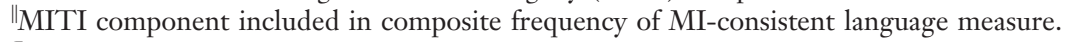

${ }^{\mathrm{I}} \mathrm{MITI}$ ratio definitions: percentage adherent to $\mathrm{MI}=\mathrm{MI}$-adherent statements/(MI-adherent statements + MI-nonadherent statements); percentage of $\mathrm{OC}=$ open questions/(open questions + closed questions); percentage of complex reflections $=$ complex reflections/(complex reflections + simple reflections); reflection-to-question ratio $=($ simple + complex reflections $) /($ closed + open questions $)$. 
Table 5. Association between Motivational Interviewing (MI) Trainings Attended and MI Performance and Global Rating

\begin{tabular}{|c|c|c|c|c|}
\hline \multirow[b]{2}{*}{ MI Measure } & \multicolumn{4}{|c|}{ Training Sessions } \\
\hline & $\begin{array}{l}3 \text { Sessions } \\
(\mathrm{n}=47)\end{array}$ & $\begin{array}{l}2 \text { Sessions } \\
(\mathrm{n}=21)\end{array}$ & $\begin{array}{l}1 \text { Session } \\
(\mathrm{n}=17)\end{array}$ & $\begin{array}{l}\text { Control } \\
(\mathrm{n}=86)\end{array}$ \\
\hline \multicolumn{5}{|l|}{ MI performance score } \\
\hline $\begin{array}{l}\text { MI-consistent statement rate (per } \\
10 \text { minutes of the encounter) } \\
(95 \% \mathrm{CI})\end{array}$ & $9.59(8.5-10.7)$ & $8.55(7.0-10.2)$ & $6.92(5.1-8.7)$ & $6.96(6.2-7.8)$ \\
\hline $\begin{array}{l}3 \text { MI training sessions vs } \\
\text { comparator, Cohen d }(95 \% \\
\text { CI), } P \text { value }\end{array}$ & & 0.28 ( -0.21 to 0.77$), .290$ & $0.72(0.21-1.24), .012$ & $0.71(0.36-1.06),<.001$ \\
\hline \multicolumn{5}{|l|}{ Global Rating } \\
\hline $\begin{array}{l}\text { Beginning Spirit in MI Spirit } \\
\text { (3.5 or higher) (95\% CI) }\end{array}$ & $0.49(0.22-0.77)$ & $0.25(0.04-0.72)$ & $0.18(0.02-0.67)$ & $0.15(0.06-0.32)$ \\
\hline $\begin{array}{l}3 \text { MI training sessions vs } \\
\text { comparator, OR ( } 95 \% \mathrm{CI}), P \\
\text { value }\end{array}$ & & $2.89(0.27-31.21), .380$ & $4.27(0.34-53.37), .26$ & $5.6(1.13-27.89), .036$ \\
\hline
\end{tabular}

Clinical effect sizes with Cohen's d: 0.2, small; 0.5, medium; 0.8, large. Clinical effect sizes with odds ratio (OR): 1.29, small; 1.88, medium; 2.79 , large. ${ }^{44}$

Both technical and relational MI performance (fMICO and MI spirit) scores were significantly higher for PCPs attending all classroom trainings relative to those attending $<2$ trainings, suggesting that additional training may have boosted MI performance. Alternatively, those PCPs more proficient in MI may have been more likely to attend refreshers but did not boost or maintain their MI performance as a result of additional training. Global direction was significantly higher for MItrained PCPs. Further analysis of audiotaped encounters would elucidate whether the finding was because of more MI-consistent reflective listening or more MI nonadherent directing.

Lack of an intervention effect on change talk specific to antidepressant medication and rates of obtaining medication may be because of patient, PCP, or other factors. Change talk around antidepressants, while associated with increased adherence to antidepressant medication in a previous study, ${ }^{27}$ may have been driven primarily by underlying patient beliefs or previous experiences with antidepressant medication. ${ }^{45}$ MI-trained PCPs may have lacked skill or time to elicit additional change talk around antidepressants but seemed to successfully elicit more change talk targeting physical activity.

Notable strengths of this study include recruitment of experienced PCPs, the randomized study design, and collection of patient-level outcomes. Weaknesses include a threat to generalizability: our specific training approach totaled up to 16 hours of paid classroom time may not translate to other medical settings. We studied a relatively small number of PCPs, and we did not prespecify a primary outcome, although summary measures of fMICO and MI spirit performance are consistent with the primary outcomes in another trial of MI training for pediatric residents. ${ }^{46} \mathrm{We}$ did not blind PCPs to patient participation, nor did we extensively evaluate the effect of training in the standard management of depression on patient outcomes. However, any related effects on outcomes would be expected to occur equally for intervention and control PCPs. Although the stratified, randomized study design would most often account for prestudy differences, we do not know how adjusting for PCPs' MI performance before training or patients' physical activity or antidepressant adherence before the study would have influenced our findings. While unlikely in part because MI-trained and control PCPs reported minimal previous $\mathrm{MI}$ training, it is possible that a PCP sample more proficient in $\mathrm{MI}$ and/or a patient sample with higher physical activity before baseline was allocated to the MI training condition by chance. The finding that MI skills that were a focus of MI training were those showing significant improvements supports the likelihood of well-balanced baseline MI skills and an effective MI training.

Because this was an effectiveness trial, we did not train PCPs to a clinical proficiency criterion. Thresholds after MI-training in the specialty arena are set by expert opinion and are relatively high, in 
part because therapists often exhibit a substantial MI capability before training. ${ }^{20,47}$ Researchers should conduct (1) studies of the effects of various training components on the acquisition and maintenance of MI skills; (2) studies of whether particular MI components are more successfully learned; and (3) moderator-mediator analyses of the effects of MI training on PCP MI performance and on patient outcomes. ${ }^{24}$ Further enhancements to the training approach may improve PCP proficiency and patient outcomes.

Health care systems are not certain about how to best approach MI training. To our knowledge, ours is the first study to demonstrate that experienced PCPs cluster-randomized to receive MI training effectively learned and applied some MI skills over a 24-month RCT recruitment period in real-world clinical settings. This multifaceted training adapted from specialty settings has potential to set a standard for MI training in primary care and may also represent an approach to helping PCPs frame clinically impactful discussions around depression.

The authors thank the nurse managers, team leaders, and staff at the Bernard Gipson Eastside, Sandos Westside, Lowry, Montbello, Park Hill, La Casa Quigg-Newton, and Family Internal Medicine clinics at Denver Health for supporting this study. The authors also thank Denver Health, Denver Community Health Services, and the Denver Health Department of Family Medicine for providing in-kind support for this research.

\section{References}

1. Miller W, Rollnick S. Motivational interviewing: helping people change. 3rd ed. New York: Guilford Press; 2013.

2. Lundahl B, Burke BL. The effectiveness and applicability of motivational interviewing: a practicefriendly review of four meta-analyses. J Clin Psychol 2009;65:1232-45.

3. Soderlund LL, Madson MB, Rubak S, Nilsen P. A systematic review of motivational interviewing training for general health care practitioners. Patient Educ Couns 2011;84:16-26.

4. Kalet AL, Gillespie CC, Schwartz MD, et al. New measures to establish the evidence base for medical education: identifying educationally sensitive patient outcomes. Acad Med 2010;85:844-51.

5. Gelenberg A, Markowitz J, Rosenbaum J, Thase M, Trivedi M, Van Rhoads R. Practice guideline for the treatment of major depressive disorder. 3rd ed. Arlington, VA: American Psychiatric Publishing; 2010.

6. Lepine JP, Briley M. The increasing burden of depression. Neuropsychiatr Dis Treat 2011;7:3-7.
7. Kovess-Masfety V, Alonso J, Brugha TS, Angermeyer MC, Haro JM, Sevilla-Dedieu C. Differences in lifetime use of services for mental health problems in six European countries. Psychiatr Serv 2007;58: 213-20.

8. Bilsker D, Goldner EM, Jones W. Health service patterns indicate potential benefit of supported selfmanagement for depression in primary care. Can J Psychiatry 2007;52:86-95.

9. Shim RS, Baltrus P, Ye J, Rust G. Prevalence, treatment, and control of depressive symptoms in the United States: results from the National Health and Nutrition Examination Survey (NHANES), 20052008. J Am Board Fam Med 2011;24:33-8.

10. Fernandez A, Haro JM, Martinez-Alonso M, et al. Treatment adequacy for anxiety and depressive disorders in six European countries. Br J Psychiatry. 2007;190:172-3.

11. Kessler RC, Berglund P, Demler O, et al. The epidemiology of major depressive disorder: results from the National Comorbidity Survey Replication (NCS-R). JAMA 2003;289:3095-105.

12. Simon GE, Von Korff M, Rutter CM, Peterson DA. Treatment process and outcomes for managed care patients receiving new antidepressant prescriptions from psychiatrists and primary care physicians. Arch Gen Psychiatry 2001;58:395-401.

13. Trivedi MH, Lin EH, Katon WJ. Consensus recommendations for improving adherence, self-management, and outcomes in patients with depression. CNS Spectr 2007;12:1-27.

14. Sikorski C, Luppa M, Konig HH, van den Bussche H, Riedel-Heller SG. Does GP training in depression care affect patient outcome? A systematic review and meta-analysis. BMC Health Serv Res 2012;12:10.

15. Huibers MJ, Beurskens AJ, Bleijenberg G, van Schayck CP. Psychosocial interventions by general practitioners. Cochrane Database Syst Rev. 2007; 18: CD003494.

16. Arkowitz H, Burke BL. Motivational interviewing as an integrative framework for the treatment of depression. In: Arkowitz H, Westra HA, Miller WR, Rollnick S (eds.). Motivational interviewing in the treatment of psychological problems. New York: Guilford Press; 2008:145-72.

17. Kertes A, Westra HA, Angus L, Marcus M. The impact of motivational interviewing on client experiences of cognitive behavioral therapy for generalized anxiety disorder. Cogn Behav Prac 2011;18:55-69.

18. Lundahl B, Moleni T, Burke BL, et al. Motivational interviewing in medical care settings: a systematic review and meta-analysis of randomized controlled trials. Patient Educ Couns 2013;93:157-68.

19. Vanbuskirk KA, Wetherell JL. Motivational interviewing with primary care populations: a systematic review and meta-analysis. J Behav Med 2014;37:768-80. 
20. Miller WR, Yahne CE, Moyers TB, Martinez J, Pirritano M. A randomized trial of methods to help clinicians learn motivational interviewing. J Consult Clin Psychol 2004;72:1050-62.

21. Moyers TB, Manuel JK, Wilson P, Hendrickson SML, Talcott W, Durand P. A randomized trial investigating training in motivational interviewing for behavioral health providers. Behav Cogn Psychother 2008;36:136-62.

22. Rollnick S, Miller WR, Butler C. Motivational interviewing in health care: helping patients change behavior. New York: Guilford Press; 2008.

23. Walters ST, Matson SA, Baer JS, Ziedonis DM. Effectiveness of workshop training for psychosocial addiction treatments: a systematic review. J Subst Abuse Treat 2005;29:283-93.

24. Miller WR, Rose GS. Toward a theory of motivational interviewing. Am Psychol 2009;64:527-37.

25. Moyers TB, Martin T, Christopher PJ, Houck JM, Tonigan JS, Amrhein PC. Client language as a mediator of motivational interviewing efficacy: where is the evidence? Alcohol Clin Exp Res 2007;31:40S-7S.

26. Baer JS, Beadnell B, Garrett SB, Hartzler B, Wells EA, Peterson PL. Adolescent change language within a brief motivational intervention and substance use outcomes. Psychol Addict Behav 2008;22:570-5.

27. Kaplan JE, Keeley RD, Engel M, Emsermann C, Brody D. Aspects of patient and clinician language predict adherence to antidepressant medication. J Am Board Fam Med 2013;26:409-20.

28. Li C, Friedman B, Conwell Y, Fiscella K. Validity of the Patient Health Questionnaire 2 (PHQ-2) in identifying major depression in older people. J Am Geriatr Soc 2007;55:596-602.

29. Huang FY, Chung H, Kroenke K, Delucchi KL, Spitzer RL. Using the Patient Health Questionnaire-9 to measure depression among racially and ethnically diverse primary care patients. J Gen Intern Med 2006;21:547-52.

30. Schraufnagel TJ, Wagner AW, Miranda J, Roy-Byrne PP. Treating minority patients with depression and anxiety: what does the evidence tell us? Gen Hosp Psychiatry 2006;28:27-36.

31. Murphy E, Hou L, Maher BS, et al. Race, genetic ancestry and response to antidepressant treatment for major depression. Neuropsychopharmacology 2013;38:2598-606.

32. Bao Y, Alexopoulos GS, Casalino LP, et al. Collaborative depression care management and disparities in depression treatment and outcomes. Arch Gen Psychiatry 2011;68: 627-36.

33. Rivero-Santana A, Perestelo-Perez L, Perez-Ramos J, Serrano-Aguilar P, De Las Cuevas C. Sociodemographic and clinical predictors of compliance with antidepressants for depressive disorders: systematic review of observational studies. Patient Prefer Adherence 2013;7:151-69.
34. Martino S, Carroll KM, Ball SA. Teaching, monitoring and evaluating motivational interviewing practice. In: Tober G, Raistrick D (eds.). Motivational dialogue: preparing addiction professionals for motivational interviewing practice. New York: Routledge/Taylor \& Francis Group; 2007:87-113.

35. Moyers TB, Martin T, Manuel JK, et al. Revised Global Scales: Motivational Interviewing Treatment Integrity (MITI) 3.1.1. University of New Mexico Center on Alcoholism, Substance Abuse, and Addictions 2010. Available from: http://www.motivationalinterview.org/ Documents/miti3_1.pdf. Accessed August 7, 2014.

36. Miller WR. The Motivational Interviewing Skill Code (MISC) manual. University of New Mexico Center on Alcoholism, Substance Abuse, and Addictions. Available from: http://casaa.unm.edu/download/ misc1.pdf. Accessed August 7, 2014.

37. Moyers TB, Martin T, Manuel JK, Hendrickson SM, Miller WR. Assessing competence in the use of motivational interviewing. J Subst Abuse Treat 2005; 28:19-26.

38. Miller WR, Moyers, TB, Ernst D, et al. Manual for the Motivational Interviewing Skill Code (MISC) 2.1. University of New Mexico Center on Alcoholism, Substance Abuse, and Addictions. Available from: http://casaa.unm.edu/download/misc.pdf. Accessed August 7, 2014.

39. Glasgow RE, Wagner EH, Schaefer J, Mahoney LD, Reid RJ, Greene SM. Development and validation of the Patient Assessment of Chronic Illness Care (PACIC). Med Care 2005;43:436-44.

40. CONSORT 2010. Lancet. 2010;375: 1136.

41. Demyttenaere K, Van Ganse E, Gregoire J, Gaens E, Mesters P. Compliance in depressed patients treated with fluoxetine or amitriptyline. Belgian Compliance Study Group. Int Clin Psychopharmacol 1998;13:11-7.

42. Altman DG. Practical statistics for medical research. Boca Raton, FL: CRC Press; 1990.

43. Hox JJ. Multilevel analysis: techniques and applications. Florence, KY: Psychology Press, 2002.

44. Kraemer HC, Kupfer DJ. Size of treatment effects and their importance to clinical research and practice. Biol Psychiatry 2006;59:990-6.

45. Aikens JE, Nease DE, Nau DP, Klinkman MS, Schwenk TL. Adherence to maintenance-phase antidepressant medication as a function of beliefs about medication. Ann Fam Med 2005;3:23-30.

46. Lozano P, McPhillips HA, Hartzler B, et al. Randomized trial of teaching brief motivational interviewing to pediatric trainees to promote healthy behaviors in families. Arch Pediatr Adolesc Med 2010; 164:561-6.

47. Schoener EP, Madeja CL, Henderson MJ, Ondersma SJ, Janisse JJ. Effects of motivational interviewing training on mental health therapist behavior. Drug Alcohol Depend 2006;82:269-75. 
Appendix 1

Relational and Technical Domains of Motivational

Interviewing

Table 6. Components of Motivational Interviewing (MI)

\begin{tabular}{lll}
\hline Components $^{1,2}$ & Definition & Examples/Rating Scheme \\
\hline
\end{tabular}

Relational domain MI Spirit

Empathy

Technical domain

MI-adherent statements
MI spirit is exemplified by collaboration in all areas of MI practice; eliciting and respecting the client's ideas, perceptions, and opinions; eliciting and reinforcing the client's autonomy and choices; and accepting the client's decisions.

The spirit of MI has 3 foundations:

1. Collaboration: Collaboration between the primary care provider and the patient or "client" builds a trusting relationship.

2. Evocation:- Helping the client to voice their own ideas and reasons for change.

3. Autonomy/support: The provider supports the patient as the agent of change, and the patient is responsible for following through or not. The provider is supportive of the patient regardless of whether and how they decide to change.

Expressing empathy includes expressing understanding of the patient's lived experience or seeing, feeling, and experiencing the world through the patient's eyes.

This category is used to capture particular interviewer behaviors that are consistent with a motivational interviewing approach.

Affirmation: The provider says something positive or complementary to the client; may be in the form of appreciation, confidence, or reinforcement. The provider comments on the client's strengths or efforts.

Emphasize autonomy: The provider recognizes the client's freedom of choice, autonomy, and ability to decide.

Asking permission before giving advice or permission: Asking what the client already knows or has already been told about a topic before giving advice or information.

Support: The provider makes a statement that takes on a compassionate, sympathetic, supportive, or agreeing quality.
Average of global scores of evocation, collaboration, and autonomy/support (scales of 1 to 5 ; percentage highest; average, 3 ); providers score high on collaboration when they negotiate with the client, respect the client's ideas about how change can occur, avoid persuasion, and focus on supporting the client's own concerns and ideas. Confrontational, authoritative, and rigid providers score low on collaboration.

Higher scores on evocation result when the provider draws out the client's ideas as opposed to instilling knowledge, insights, and advice. Lower scores are ascribed to providers who show little interest in the client's perspective or display cynicism about prospects for change.

Higher scores for autonomy/support occur when the provider readily accepts the client's decisions not to change at that particular moment. This provider recognizes that critical factors predicting change reside within the client. Low autonomy/support is typified by an urgency to change and lack of acceptance of the client's capability to decide to change or not; client freedom of choice and self-determination is not recognized in this instance.

Range 1 to 5 (higher is better; average, 3); high empathy is characterized by the provider showing active interest in the client's perspectives, including situation, meaning, perceptions, and feelings. Low empathy is characterized by a lack of interest in the client's perspectives and experiences. Probing for factual information and pursuing an agenda are examples of low empathy.

"It takes courage to come in and talk about depression." (Affirm)

"You've got a point there." (Emphasizing the client's control)

"May I share some information about antidepressant medications?" (Ask permission)

"Well, there is really a lot going on for you right now." (Support) 
Table 6. Continued

\begin{tabular}{|c|c|c|}
\hline Components $^{1,2}$ & Definition & Examples/Rating Scheme \\
\hline Open-ended questions & $\begin{array}{l}\text { An open question is coded when the } \\
\text { interviewer asks a question that allows a } \\
\text { wide range of possible answers. The } \\
\text { question may seek information, invite the } \\
\text { client's perspective, or encourage self- } \\
\text { exploration. The open question allows the } \\
\text { option of surprise for the questioner. } \\
\text { "Tell me more" statements are coded as open } \\
\text { questions unless the tone and context } \\
\text { clearly indicate a direct or confront code. }\end{array}$ & "What is your take on that?" (Open question) \\
\hline $\begin{array}{l}\text { Reflective statements } \\
\text { (simple and complex) }\end{array}$ & $\begin{array}{l}\text { This category is meant to capture reflective } \\
\text { listening statements made by the provider } \\
\text { in response to client statements. A } \\
\text { reflection may introduce new meaning or } \\
\text { material, but it essentially captures and } \\
\text { returns to clients something about what } \\
\text { they have just said. } \\
\text { Simple: Simple reflections typically convey } \\
\text { understanding or facilitate client/provider } \\
\text { exchanges. These reflections add little or } \\
\text { no meaning (or emphasis) to what clients } \\
\text { have said. } \\
\text { Complex: Complex reflections typically add } \\
\text { substantial meaning or emphasis to what } \\
\text { the client has said. These reflections serve } \\
\text { the purpose of conveying a deeper or more } \\
\text { complex picture of what the client has said. } \\
\text { Sometimes the provider may choose to } \\
\text { emphasize a particular part of what the } \\
\text { client has said to make a point or take the } \\
\text { conversation in a different direction. }\end{array}$ & $\begin{array}{l}\text { "You are determined to start an antidepressant } \\
\text { medication." (Simple reflection) } \\
\text { "On the one hand you perceive potential } \\
\text { benefit from the medicine, and on the other } \\
\text { hand you are terrified of getting addicted." } \\
\text { (Complex reflection) }\end{array}$ \\
\hline MI-consistent language & $\begin{array}{l}\text { MI adherent statements }+ \text { reflections }+ \text { open } \\
\text { questions }\end{array}$ & \\
\hline Rulers & $\begin{array}{l}\text { The confidence and importance rulers invite } \\
\text { the client to rate their confidence or } \\
\text { importance on a } 0 \text { to } 10 \text { scale regarding } \\
\text { making a target behavior change. }\end{array}$ & $\begin{array}{l}\text { The provider may implement the rulers to } \\
\text { evoke client "change talk," or language } \\
\text { toward making a specific behavior change. } \\
\text { When the client provides a number, eg, "5," } \\
\text { the provider can ask, "Why did you say '5' } \\
\text { and not '2'?" which evokes reasons for } \\
\text { change. Alternatively, the provider might say, } \\
\text { "What would it take to raise the '5' to an } \\
\text { '8'?, which also evokes change talk. The } \\
\text { process involves } 2 \text { open questions. }\end{array}$ \\
\hline $\begin{array}{l}\text { Ask-provide-ask or } \\
\text { elicit-provide-elicit }\end{array}$ & $\begin{array}{l}\text { The ask-provide-ask tool is an MI-consistent } \\
\text { approach to sharing information. First, the pro- } \\
\text { vider asks permission to share information, then } \\
\text { with permission shares information, and follows } \\
\text { by asking the client what they think or how } \\
\text { they are reacting to the information. A variant } \\
\text { is the elicit-provide-elicit approach for garner- } \\
\text { ing learning about a client's thoughts or per- } \\
\text { spectives, sharing information or one's perspec- } \\
\text { tives with permission, then eliciting more of the } \\
\text { client's perspectives and change talk. }\end{array}$ & $\begin{array}{l}\text { The provider firsts asks permission to share } \\
\text { information by asking, for example, "Would } \\
\text { you be interested in hearing more about } \\
\text { possible treatment options for depression?" If } \\
\text { the patient assents, the provider can then } \\
\text { provide information, then ask about or elicit } \\
\text { the client's thoughts, eg, by asking "What do } \\
\text { you think about those options?" }\end{array}$ \\
\hline $\begin{array}{l}\text { Elaborate, affirm, } \\
\text { reflect, summarize }\end{array}$ & $\begin{array}{l}\text { When a provider recognizes change talk, the goal } \\
\text { is to reinforce the change talk. The provider } \\
\text { then asks the patient to elaborate on what they } \\
\text { meant using evocative questions, affirms the } \\
\text { patient's statements toward positive change, and } \\
\text { reflects the change talk. This approach often } \\
\text { elicits more change talk. The provider then } \\
\text { summarizes the patient's change talk, any plans } \\
\text { to change, and strengths. }\end{array}$ & \\
\hline
\end{tabular}


Table 6. Continued

\begin{tabular}{|c|c|c|}
\hline Components ${ }^{1,2}$ & Definition & Examples/Rating Scheme \\
\hline Giving information & $\begin{array}{l}\text { If the provider gives information, educates, } \\
\text { provides feedback, or discloses personal } \\
\text { information, it is considered "giving } \\
\text { information." }\end{array}$ & $\begin{array}{l}\text { An example would be feedback from a } \\
\text { depressive symptom scale. "You scored a } 19 \\
\text { on the depressive symptoms scale, which is } \\
\text { consistent with moderately severe depressive } \\
\text { symptoms." }\end{array}$ \\
\hline Closed questions & $\begin{array}{l}\text { Closed questions can be answered with a } \\
\text { "yes" or "no." }\end{array}$ & $\begin{array}{l}\text { "Have you been taking your antidepressant } \\
\text { medication as prescribed?" }\end{array}$ \\
\hline $\begin{array}{l}\text { MI-nonadherent } \\
\text { statements }\end{array}$ & $\begin{array}{l}\text { Advising, directing, confronting } \\
\text { Advising without permission involves } \\
\text { uninvited advice, suggestions, or a solution. } \\
\text { Direct- involves a command, direction, or } \\
\text { order. } \\
\text { A confrontation involves expert-like responses } \\
\text { that have a particular negative/parental } \\
\text { quality, an uneven power relationship } \\
\text { accompanied by disapproval, disagreement, } \\
\text { or negativity. } \\
\text { The provider may directly disagree, argue, } \\
\text { correct, shame, blame, seek to persuade, } \\
\text { criticize, judge, label, moralize, ridicule, or } \\
\text { question the client's honesty. }\end{array}$ & $\begin{array}{l}\text { "I'd recommend that you start an } \\
\text { antidepressant medication." (Advising) } \\
\text { "At this point, you really need to get some } \\
\text { therapy." (Direct) } \\
\text { "It's evident to me that you are not taking your } \\
\text { medicine." (Confrontation) }\end{array}$ \\
\hline
\end{tabular}

\section{Appendix 2 \\ Reliability Scores and Coefficients of Intracluster Correlation \\ Coder Training}

Three coders (RDK, ME, JK) participated in a basic 16-hour MITI training course, and the primary coder (JK) received an additional 14 hours of advanced training. Coders met weekly for 1 to 2 hours over 6 months to discuss relevant issues and decide how to uniformly address coding challenges.

\section{Reliability}

The 3 coders scored a subset of audiotaped encounters to establish reliability. However, only the blinded primary coder scored all baseline encounters, and her MITI scores were used for analytical purposes. ${ }^{3}$ Scores from all coders were used for analyses of change talk. Cronbach $\alpha$ was used to assess agreement between coders for continuous measures, ${ }^{4}$ and the Cohen $\kappa$ statistic was used for dichotomous and categorical measures.

A total of 75 tapes were randomly selected to include at least 2 tapes from each participating provider. Tapes were coded to assess MITI behavior counts, global ratings scores, change talk, ${ }^{1,2}$ and "prescription provided" and "physical activity recommended."

Interpretation of the intraclass correlations were poor $(<0.40)$, fair $(0.40-0.59)$, good $(0.60-$
$0.74)$, or excellent $(0.75-1.00)$; and $\kappa$ coefficients were interpreted as poor $(\leq 0.20)$, fair $(0.21-$ $0.40)$, moderate (0.41-0.60), good (0.61-0.80), and very good $(0.81-1.00){ }^{5}$

The following tables show reliability results.

\section{Coefficients of Intracluster Correlation}

Coefficients of intracluster correlation, considering the provider as the unit of clustering, were generated.

\section{References}

1. Moyers TB, Martin T, Manuel JK, Hendrickson SM, Miller WR. Assessing competence in the use of motivational interviewing. J Subst Abuse Treat 2005;28: 19-26.

2. Miller WR, Moyers TB, Ernst DB, Amrhein PC. Motivational Interviewing Skill Code (MISC) version

\section{Table 7. Kappa Coefficients for Dichotomous and Ordinal Measures}

\begin{tabular}{lc}
\hline Measure & $\kappa$ \\
Value*
\end{tabular}

*Using normal approximation to test $\mathrm{H}_{0}$ : no agreement. 
Table 8. Intraclass Correlation Coefficients (ICCs) for Continuous Measures

\begin{tabular}{lc}
\hline Measure & ICC \\
\hline fMICO (rate) & 0.74 \\
MI spirit & 0.54 \\
MI-adherent statements, \% & 0.61 \\
Open questions, \% & 0.70 \\
Complex reflections, \% & 0.45 \\
Giving information (adjusted for time) & 0.79 \\
Change talk pertaining to ways to handle depression & 0.83 \\
$\quad$ (rate) & \\
Change talk around medications for depression (rate) & 0.85 \\
Change talk around physical activity (rate) & 0.76 \\
\hline
\end{tabular}

fMICO, frequency of MI-consistent language; MI, motivational interviewing.

2.1. New Mexico: Center on Alcoholism, Substance Abuse, and Addictions, The University of New Mexico; 2008.

3. Kaplan JE, Keeley RD, Engel M, Emsermann C, Brody D. Aspects of patient and clinician language predict adherence to antidepressantmedication. J Am Board Fam Med 2013;26:409-20.
Table 9. Coefficients of Intracluster Correlation*

\begin{tabular}{ll}
\hline Measure & By Provider \\
\hline Rate of MI-consistent language & 0.009 \\
MI spirit (1-5) & 0.48 \\
Beginning proficiency in MI spirit $(\geq 3.5)$ & 0.22 \\
Prescription for antidepressant provided & 0.00 \\
Recommendation of physical activity & 0.0005 \\
Change talk regarding depression treatment & 0.021 \\
$\quad$ frequency & \\
Change talk specific to antidepressant & 0.010 \\
$\quad$ medication frequency & 0.0036 \\
Change talk specific to physical activity & \\
$\quad$ frequency & 0.014 \\
Physical activity & 0.056
\end{tabular}

*Coefficients of intracluster correlation are considered small $(<0.05)$, medium $(<0.15)$, or large $(>0.15) .{ }^{43}$

MI, motivational interviewing.

4. Shrout PE, Fleiss JL. Intraclass correlations: uses in assessing rater reliability. Psychol Bull. 1979;86:420-8.

5. Altman D. Practical statistics for medical research. London: Chapman and Hall; 1991. 